Documento 



\title{
Ser mulher e escritora no Brasil
}

\author{
Marina Colasanti
}

Que fique claro, não se trata aqui de fazer um percurso histórico pela literatura feminina brasileira. Nem nos interessa enfileirar nomes que, sem maiores referências, acabariam não tendo sentido. Minha intenção é fazermos breves paradas naquelas esquinas em que o fato de escrever e o de ser mulher se cruzam, e analisar a presença feminina no universo dos livros não apenas do ponto de vista literário, mas também como uma questão social. Cada um dos itens que levantarei poderia ser amplamente desenvolvido, e todos podem ser intercambiados à vontade.

1.

Podemos afirmar que ser mulher e escritora no Brasil é muito difícil.

Assim como podemos afirmar que ser escritora e mulher no Brasil é muito fácil.

As duas afirmações são igualmente válidas. Qualquer conversa sobre o feminino brasileiro deve partir do fato de que não existe uma única mulher brasileira ou uma brasileira padrão. A garota de Ipanema, biquíni, sensualidade e pele queimada é, mais que um mito, uma peça de propaganda quase ficcional. A realidade é múltipla, e bem mais complexa.

Ser escritora no Brasil é fácil porque os preconceitos são bem reduzidos, sobretudo em relação ao passado. Porque existem creches. E porque ainda - embora cada dia menos - é possível dispor de ajuda para cuidar de filhos e casa, mantendo livre um espaço de tempo pessoal. Porque as universidades estão cheias de mulheres, e há mais mulheres do que homens fazendo cursos de pós-graduação - nos cursos de Letras, assim como nos eventuais cursos de criação literária, a preponderância feminina é notável. E porque também no Brasil, como no mundo inteiro, as mulheres leem mais do que os homens.

Mas ao mesmo tempo, ser escritora no Brasil é muito difícil porque os preconceitos ainda existem. E porque faltam creches, e as mães de família acumulam trabalho na rua e trabalho doméstico, pouco podendo contar com a ajuda do companheiro, quando existe um. Porque até tempos recentes - falo de uma geração apenas -, havendo poucos recursos para a educação dos filhos, esses recursos eram canalizados para os meninos. Porque as meninas, mais que os meninos, são mantidas em casa para ajudar a cuidar dos irmãos menores. Porque a gravidez adolescente é cada dia mais frequente, afastando as jovens do estudo e das possibilidades profissionais. E porque entre os pobres, os mais pobres são sempre as mulheres, e a extrema pobreza não favorece a vida literária. 
Estão aí, simplificados, dois universos de possibilidades completamente diferentes, um para as mulheres de classe média, outro para as da pobreza e miséria.

Pobreza e miséria, também atingem os homens, é claro. E tampouco lhe favorecem o acesso às letras. Mas enquanto encontramos muitos escritores brasileiros de sucesso oriundos das classes mais carentes, os exemplos femininos são reduzidíssimos. As escritoras brasileiras pertencem quase exclusivamente à classe média.

É provável que uma razão a mais esteja no sistema das migrações. As levas constantes que migram do campo e dos pequenos centros para as capitais e as grandes cidades são prevalentemente masculinas. As mulheres casadas ficam para trás cuidando dos filhos e esperando - muitas vezes em vão - a chamada do marido. As solteiras ficam para trás porque mais vulneráveis para o enfrentamento das cidades grandes, e porque há sempre um pai ou uma mãe de idade que não se pode abandonar. E é nos grandes centros que as ideias fermentam e que o talento literário tem espaço para crescer. É provável que num futuro próximo o advento da internet venha a mudar esse quadro. Mas, por enquanto, os filhos da internet ainda estão verdes.

2.

Uma das estrelas mais refulgentes da moderna literatura brasileira é mulher: Clarice Lispector. Sou quase tentada a dizer "a estrela mais refulgente”, porém a seu lado e com luz equivalente cintilam Guimarães Rosa e o poeta Carlos Drummond de Andrade.

Clarice é, ou foi, uma mulher que escapa dos dois universos aos quais acabei de me referir. Uma mulher que não vem da miséria nem das classes altas, que sempre se considerou brasileira embora tivesse nascido na Ucrânia, que tendo estudado e lido os grandes autores gerou uma escrita absolutamente nova e sem paralelo.

Com meu marido, Affonso Romano de Sant'Anna, acabamos de entregar ao editor um livro sobre ela - Com Clarice (São Paulo: Editora da UNESP, a sair). Esse livro contém, além de outros textos, um longo depoimento gravado em 1976 para o Museu da Imagem e do Som, em que nós dois, e o diretor do Museu, atuamos como entrevistadores. Um depoimento alegre, de uma leveza pouco usual nela, em que percorreu, rindo por vezes de si mesma e da existência, sua infância, sua juventude e a vida literária.

Eu disse que Clarice não vem da miséria, mas isso é só parcialmente verdade. Vem de uma pobreza diferente, a pobreza dos emigrantes, que não têm recursos mas têm determinação, que lutam com dificuldades mas investem na formação dos filhos o pouco que conseguem obter. Não se trata aqui de fazer a biografia de Clarice (aconselho, a quem estiver interessado, o completíssimo livro do americano Benjamin Moser (Clarice. São Paulo: Cosac Naify, 2011), baste dizer que, filha de judeus russos, mesmo quando a 
situação econômica familiar era muito precária, estudou em bons colégios, estudou piano e francês, formou-se em Direito. E, desde menina, leu.

Haverá quem diga que Clarice nunca chegou às letras, nasceu com elas. De fato, começou a escrever contos ainda menina, enviando-os para concursos promovidos por revistas ou jornais - a maioria, como ela conta no depoimento, não era aceita porque os seus contos não tinham enredo, característica que ressurgiria nos seus mais importantes romances. Foi mais bem sucedida nos tempos da faculdade quando, novamente buscando revistas, publicou alguns contos. E aos 24 anos publicou seu primeiro romance, Perto do Coração Selvagem.

O interessante é que a escrita de Clarice já começou pronta. No tempo em que meu marido era chefe do departamento de Letras da PUC do Rio de Janeiro, Clarice trouxe para ele alguns textos inéditos que queria negociar, não em termos editoriais, mas universitários. Dizia tê-los escrito aos 15 anos. Fossem 15 ou algo mais - as datas, com Clarice, são sempre questionáveis porque ela mentia a idade -, surpreendeu-nos a maturidade daqueles textos, de estilo já claramente definido.

Se Clarice de fato nasceu com as letras, foi, porém, como muitas mulheres brasileiras antes dela, através do jornalismo que ingressou na literatura.

Aos 20 anos conseguiu seu primeiro emprego, inicialmente como tradutora e logo como redatora e repórter, em um organismo de propaganda do governo. O jornalismo era naquele tempo o refúgio primeiro dos jovens escritores, e o fato de ela ter convivido ali com alguns escritores mais velhos e já experientes foi determinante para a sua vida literária.

Trabalhou depois em outras publicações. E, mais tarde, por três vezes, e em três jornais diferentes, foi autora de sessões femininas. Era um destino quase inevitável para as mulheres jornalistas de então, e o foi mesmo depois, como eu própria tive oportunidade de verificar. Clarice o fez para ganhar algum dinheiro, e sempre com pseudônimo. Os títulos não eram exatamente criativos, e é provável que fossem idealizados pelos editores: "Entre Mulheres”, “Correio Feminino” e "Só Para Mulheres”. E embora os dois primeiros pseudônimos fossem anódinos e inventados por ela, na terceira investida assinou com o nome de uma atriz belíssima e famosa, a pedido do editor e com a conivência da atriz.

Durante toda a sua carreira de escritora, que descreveu até o fim um percurso em ascensão, Clarice continuou vinculada à imprensa. Eu própria fui sua editora durante os seis anos em que assinou uma sessão semanal no Jornal do Brasil, então um dos mais importantes do país. E trabalhou longos anos em uma revista de grande tiragem, fazendo entrevistas longas, sobretudo com pessoas amigas, da arte e da literatura.

Não eram ainda tempos muito favoráveis à escrita das mulheres, e a venda dos seus livros, embora já amplamente apreciados no universo 
literário, não teria sido suficiente para sustentá-la depois do fim do seu casamento.

Olhando as críticas a seus livros publicadas sobretudo na primeira parte da sua carreira, percebe-se o preconceito, embora velado. Reconhecendo a qualidade da sua escrita e declarando-a inovadora, nenhuma das críticas deixa de qualificá-la como "feminina", mantendo com isso bem claro que pertence a outra estirpe, não concorrendo com a literatura dos homens.

3.

Falei da atividade jornalística de Clarice e não exatamente da sua obra, por duas razões. Primeiro porque ao preparar este texto tinha certeza de que a obra dessa imensa escritora seria tratada nesta Feira (25a. Feira do Livro de Bogotá, 2012) em outro momento, e por alguém até mais qualificado do que eu, como de fato aconteceu. Segundo porque a minha intenção, declarada no princípio, é trabalhar nosso tema de olho no coletivo, mais do que no particular. E o jornalismo aparece muito cedo na história da literatura feminina brasileira.

No livro História Concisa da Literatura Brasileira, do professor Alfredo Bosi, um dos livros mais importantes, se não o mais importante para o estudo das letras no Brasil, a primeira mulher só aparece na página 257. Chamava-se Francisca Julia, era poeta e, tendo sido parnasiana, acabou simbolista. Também ela começou escrevendo para uma revista.

Na verdade, a presença das mulheres na literatura brasileira não começou em página tão adiantada da nossa história, mas começou tarde. E não sem razão. $\mathrm{O}$ acesso à educação sempre foi muito mais espinhoso para elas. A primeira legislação relativa à educação das mulheres data de 1827, e só lhes permitia estudar nas escolas elementares, vetando seu acesso ao ensino secundário. Somente em 1879, e devido inclusive à pressão das mulheres que se atreviam a escrever em jornais e revistas, o governo lhe deu acesso à educação superior. Uma abertura legal, mas sobretudo simbólica, porque a educação secundária, que permitiria alcançar a universidade, continuava muito problemática para elas, sendo a quase totalidade das escolas desse nível só para meninos. Só com a chegada do século XX a equiparação escolar seria alcançada.

É um atraso considerável, sobretudo se pensarmos em relação ao grande surto de escritoras do romantismo europeu na primeira metade do século XIX, com as irmãs Bronte, Jane Austen, George Sand, George Eliot, além da americana Emily Dickinson. Entretanto, como resultado da política portuguesa de proibir a educação visando evitar o fermentar de ideias libertárias, os homens também não estavam adiantados.

É importante lembrar que a corte portuguesa só se mudou para o Brasil na primeira década do século XIX, e que com ela, em ares de modernidade, chegou a técnica de impressão e os primeiros livros começaram a ser publicados. 
Por isso tudo, acrescido do preconceito que mantinha as mulheres quase reclusas nas casas, a presença sensível da escrita feminina não começa pelos livros, começa por revistas. Não são revistas exclusivamente literárias, nem são dirigidas a homens e mulheres. São revistas femininas, de viés mais político que literário, abolicionistas, libertárias, em defesa da educação para as mulheres. Mas abrigam poesia e textos literários. E são o primeiro espaço que se abre às que desejam escrever.

A primeira dessas revistas é O Jornal das Senhoras. Não vou fazer uma lista, vou utilizar esta revista inaugural como amostra do conteúdo e das dificuldades da empreitada. Ela nasce no primeiro dia do ano 1852. Sua editora é uma argentina, já separada do primeiro marido, consciente dos riscos que corre ao publicar uma revista que, por suas idéias modernas, despertará a hostilidade dos homens e a retração amedrontada de boa parte das mulheres. Sua intenção é tratar dos direitos da mulher, questionar sua posição de inferioridade no casamento, e abrigar textos literários.

Já no primeiro número solicita, vivamente, colaborações das leitoras. A revista precisa delas para sobreviver. E adverte que, para salvaguarda das eventuais colaboradoras, o anonimato será mantido. Não é necessário revelar o nome sequer à editora. Algumas mulheres cultas, conhecedoras de outras línguas, oferecem traduções de artigos estrangeiros, e seus próprios textos. É a primeira porta que se abre para elas. Mas até a sessão de moda é apresentada anonimamente.

Deverão passar cerca de quatro anos antes que algumas colaboradoras de $O$ Jornal das Senhoras se atrevam a assinar com seus próprios nomes. Enquanto isso, os poucos homens que passam a colaborar se assinam imediatamente.

Que possibilidades financeiras têm, naquele momento, uma revista como essa, que aposta em pensamentos perigosos e em ensaios literários femininos? Praticamente nenhuma. De fato, a editora argentina é obrigada a desistir depois de apenas seis meses, entregando a revista a uma das colaboradoras. Esta é uma mulher culta, filha de uma família importante. Já traduziu peças italianas e francesas, escreveu algumas críticas para o Conservatório Dramático. Mas cultura nunca foi sinônimo de dinheiro, e ela aguenta apenas um ano, passando a revista adiante, desta vez para uma mulher cujo marido pode e está disposto a investir em O Jornal das Senhoras.

As revistas passaram a se multiplicar em todo o país, com títulos como O Sexo Feminino, Eco das Damas, Miosótis, e a mais importante, A Mensageira. E quem ali escreveu contribuiu não apenas para a nascente literatura brasileira, como teve um papel social na defesa da igualdade, da educação, e naquele feminismo que apenas se esboçava.

Muitos homens escritores também passaram pelo jornalismo; para eles, porém, não era, como para as mulheres, a opção única, e sim uma escolha entre outras. 
Vale lembrar que, apesar do papel importante das revistas, e dos artigos na imprensa diária, as escritoras não se limitavam a eles. Algumas poucas, que não cabe citar aqui, publicaram livros, romances, poesia. De uma escritora dessa época, porém, faço questão de citar o nome. Não só pela importância, mas porque, sendo um nome adotado e não de batismo, me parece por si só uma criação literária. Esta jornalista e escritora do nordeste do Brasil se chamava, ou quis chamar-se, Nísia Floresta Brasileira Augusta.

4.

Vamos voltar a Clarice. Não a ela, exatamente, mas ao seu tempo. E conto um fato anedótico, para mostrar como as coisas, embora tanta água e tanto papel impresso tivessem passado debaixo das pontes, ainda não eram de todo fáceis.

De uma outra escritora brasileira se falou certamente em algum momento desta Feira, Lygia Fagundes Teles, que hoje pertence à Academia Brasileira de Letras. Pois bem, há tempos eu vinha reparando que Lygia, belíssima mulher, sempre posa séria para as fotos, de preferência com óculos na mão. Estranhava, sobretudo, porque conheço bem o seu sorriso, o seu temperamento alegre. E eis que, recentemente, numa entrevista, Lygia contou que quando ela e Clarice estavam em começo de carreira, esta lhe recomendou não sorrir diante das objetivas. "Se a gente sorrir, Lygia, eles não nos levam a sério”. Como a mulher de Cesar, não bastava ser, era preciso parecer. E Lygia, certamente mais por hábito do que por prudência, segue o conselho da amiga até hoje.

Um outro fato envolvendo Lygia vale a pena relatar. Conta o professor Antonio Cândido, voz maior no universo literário universitário, que certa feita encontrou um amigo escritor, saindo furioso de uma livraria, ou de um bar onde se reuniam escritores, não sei ao certo. Contou-lhe que havia se retirado por não suportar ver outros dois escritores "massacrando" Lygia - foi o que ele disse, textualmente - com frases como "Lygia, você é tão bonita, por que essa mania de ser escritora?” Ela chorava.

No entanto, o chão literário feminino já havia sido bastante pavimentado antes delas. Não há abalos sísmicos no Brasil, mas a movimentação cultural que sacudiu o mundo nos anos 20 foi amplamente sentida por lá. E também as nossas mulheres cortaram os cabelos repetindo a clara mensagem emitida pelas americanas e europeias: estamos libertando a cabeça do peso da tradição.

O modernismo brasileiro vê surgir artistas femininas muito interessantes, na pintura, na escultura, na música. E poetas, romancistas.

Poeta, cito apenas o nome mais brilhante, Cecília Meireles, mulher de grande elegância pessoal e carreira coerente, pedagoga inovadora, estudiosa do folclore. Não foi jornalista. Publicou seu primeiro livro de poesia aos 18 anos. 
Das romancistas, escolho duas, pela relevância e mesmo pela similitude inicial de seus percursos - percursos em grande parte ditados pela época. São elas, Pagu e Raquel de Queiroz.

Ambas nascem com espírito libertário e o manifestam desde cedo. Mas enquanto Pagu é de São Paulo e convive com o núcleo mais atuante e inovador do modernismo, Raquel é do estado do Ceará, no nordeste do Brasil, região árida e feroz, de bela cultura e sólido machismo.

Pagu começa aos 15 anos, escrevendo em jornal, e assinando-se com pseudônimo. Raquel começa aos 15 anos, escrevendo crônicas e poemas modernistas para um jornal, e assinando-se com pseudônimo. Cedo, as duas voltam seu interesse para as questões sociais.

Aos 20 anos, Raquel publica um romance inovador, $O$ quinze, cuja personagem feminina central contraria todos os estereótipos femininos ainda em uso, determinada a tecer sua vida sem incluir casamento.

Aos 20 anos, Pagu é centro de um escândalo em São Paulo, ao provocar a separação do poeta Oswald de Andrade, que se casa com ela.

As duas ingressam quase contemporaneamente no Partido Comunista. Pagu será presa 23 vezes, passará vários anos na cadeia. Raquel também será presa, uma única vez, e terá seus livros queimados durante a ditadura de Getúlio Vargas.

A partir daí, suas vidas, embora ainda semelhantes, divergem na ordem e na intensidade dos momentos. Pagu se separa de Oswald, viaja, casa-se com outro, escreve um romance, mais tarde outro, torna-se trotskista, dedica-se prevalentemente ao teatro.

Raquel também se casa, publica em sua vida cinco romances, todos de sucesso, rompe com o Partido, torna-se trotskista até o assassinato de Trotski, quando se afasta da esquerda. E escreve para o teatro. Mas apóia o golpe militar de 1964 e em várias ocasiões será representante oficial dessa nova ditadura. Em 1977, dá início à presença feminina na Academia Brasileira de Letras.

Raquel morreu tardiamente, pacífica, na rede. Pagu morreu aos 52 anos, com a mesma intensidade dramática com que viveu, de câncer.

5.

Podemos dizer que Clarice e Lygia se situam, como se sobre uma ponte literária, entre esse passado já moderno e a atualidade. Atravessam, assim, os decisivos anos 1970.

Decisivos para todos, mas sobretudo para as mulheres, que promovem uma das maiores revoluções da nossa cultura: a ruptura de paradigmas do feminino.

O feminismo é um tsunami que chega ao Brasil vindo de longe e, mais uma vez, com algum atraso. Responsável por esse atraso, o regime militar, para o qual resultava conveniente manter as mulheres caladas e 
atadas entre berço e fogão; e contra o qual se juntaram os esforços de homens e mulheres, tarefa dura e longa que impede abraçar outras frentes.

Chega com a força de um tsunami, mas dá tempo para que a quase totalidade dos homens e grande parte das mulheres busque refúgio nas antigas montanhas ideológicas. Boa parte das escritoras está entre elas.

Que nos sirva de exemplo um fato posterior do qual participei. Trata-se de um seminário, realizado em 1996 na Universidade de Illinois, sobre literatura feminina brasileira. O formato, idealizado pela especialista em literatura de mulheres, Darlene Sadlier, é interessante: participavam dele cinco escritoras brasileiras e cinco professoras americanas especializadas em sua obra. Os cinco dias foram ocupados simetricamente, pela palestra de uma escritora de manhã, e por outra à tarde apresentada pela brasilianista correspondente. O seminário era fechado, presentes apenas alguns professores e uns poucos estudantes selecionados. O titulo "Entre resistir e identificar-se” aludia ao posicionamento em relação à existência, ou não, de uma escrita feminina

As respectivas posições foram sendo assumidas com delicadeza. Das cinco escritoras, só duas consideravam que as mulheres têm um olhar diferente sobre o mundo, que olhar e escrita são uma única coisa, e que a escrita das mulheres é, sim, feminina. As outras três afirmavam que o escritor se metamorfoseia de acordo com suas personagens, e que a escrita não tem sexo. As cinco professoras americanas eram, todas elas, ligadas aos princípios da moderna crítica literária feminista.

Explica-se a reticência das três escritoras brasileiras - os nomes não interessam, interessa o contexto. Envolvidas num universo literário ainda dominado pelos homens, em que a crítica feminista era incipiente e quase que exclusivamente universitária, temiam o repúdio se apenas saíssem dos trilhos. Declarar o feminino da própria escrita dava ao sistema motivo para desqualificá-la. Por outro lado, é provável que algumas, senão todas, se sentissem mais familiarizadas, mais à vontade com os antigos dogmas.

Esse fato mostra como, passados mais de vinte anos da grande efervescência feminista, quando mudanças radicais já estavam em curso na vida das brasileiras, numerosas escritoras - justamente a classe de que se esperaria uma reflexão inovadora, e que em outras partes do mundo foi a primeira a erguer a voz - se mantinham numa prudente retaguarda.

Felizmente, não era a totalidade, e muitas delas tiveram tempo adiante para rever suas posições e atualizar seu discurso.

Desse descompasso nasceu a nova geração. As jovens mulheres brasileiras que hoje escrevem não têm mais a imprensa como única possibilidade de comunicação. São roteiristas, publicitárias, dramaturgas, multimídias. Saíram do ovo para um mundo cheio de portas, e levam ao pescoço a chave chamada internet, que abre quase todas. Para facilitar ainda mais 
a sua vida, transitam num mundo grandemente feminino. Quem vai às grandes feiras de livros internacionais sabe disso. Subindo e descendo nas escadas rolantes, transitando pelos estandes, reunindo-se em salinhas privadas, há muito mais mulheres que homens. Editoras, agentes, distribuidoras comandam o mercado, de olho no público feminino, sabendo que elas leem mais, gostam mais de poesia e ficção do que eles, falam mais de suas leituras, aconselham mais, e compram mais livros do que os homens.

Não há mais restrições à linguagem das mulheres nem à sua temática. Podem ser desabridas e violentas; aliás, é aconselhável sê-lo. Inicialmente piratas da linguagem masculina, logo torceram palavras e estilo reinventando sua própria voz. A cartilha que já estava empoeirada foi jogada definitivamente para o alto.

Definitivamente, por enquanto. Porque com grande rapidez o mercado compra as vozes inovadoras, e as multiplica, e as transforma em moda, aniquilando a inovação. Mas nesse jogo estamos todos juntos, homens e mulheres, sem distinção, buscando um lugar ao sol enquanto as nuvens se adensam no horizonte. 